\section{LA LIBERTAD REPRODUCTIVA EN DISPUTA: GESTACIÓN EN VENTA COMO OPRESIÓN}

\author{
Miguel Ángel Torres Quiroga \\ Universidad Autónoma de Madrid \\ https://orcid.org/0000-0001-7758-2473 \\ miguel.atq@gmail.com
}

\begin{abstract}
Cómo citar este artículo/Citation: Torres Quiroga, Miguel Ángel (2021). La libertad reproductiva en disputa: gestación en venta como opresión. Arbor, 197(802): a631. https://doi. org/10.3989/arbor.2021.802009
\end{abstract}

Recibido: 13 mayo 2020. Aceptado: 23 mayo 2021. Publicado: 3 febrero 2022.

RESUMEN: Comprender los dilemas éticos en torno a la subrogación de útero exige un conocimiento preciso de los conceptos de libertad y autonomía reproductiva. Una aproximación pertinente debe reconocer la naturaleza de la opresión sexual, sobre todo de cómo influye en la autonomía de las mujeres, en sus elecciones, en la identidad propia y en las relaciones interpersonales. El objetivo de este ensayo es defender la relevancia de las críticas del feminismo radical a las corrientes liberales progresistas, que a menudo prestan mayor atención a los intereses de los denominados padres intencionales. Considerando lo que varias filósofas igualitaristas han expuesto desde una perspectiva socio-relacional de la autonomía para permitir la subrogación bajo ciertas condiciones -específicamente, sostienen que la regulación es compatible con la autonomía reproductiva de las mujeres si se sigue una modalidad altruista en un ambiente de protección y apoyo ante la revocación del consentimiento-, defiendo que las feministas radicales esclarecen apropiadamente cómo la opresión contra la mujer permanece en el ambiente cultural que aprueba los contratos de subrogación. La metodología macroscópica, basada en la metáfora del ave enjaulada de la filósofa norteamericana Marilyn Frye, es una herramienta provechosa para comprender por qué la subrogación no implica una mejoría para la autonomía reproductiva de las mujeres, incluso si permite que algunas madres gestantes obtengan un ingreso suficiente para sobrellevar la presión económica.

PALABRAS CLAVE: Vientres de alquiler, gestación por sustitución, libertad reproductiva, autonomía reproductiva, opresión.

\section{REPRODUCTIVE FREEDOM IN DISPUTE: COMMERCIAL SURROGACY AS OPPRESSION}

Copyright: (C) 2021 CSIC. Este es un artículo de acceso abierto distribuido bajo los términos de la licencia de uso y distribución Creative Commons Reconocimiento 4.0 Internacional (CC BY 4.0).

ABSTRACT: Understanding the ethical concerns of paid and altruistic surrogacy requires knowledge of reproductive freedom and procreative autonomy. An accurate approach must be sensitive to the nature of sexual oppression, specifically in its influence on women's choices, self-identity, and personal relationships. The aim of this essay is to defend the relevance of radical feminism in questioning reproductive liberalism, which often focuses more on the interests of the intended parents. Keeping in mind what egalitarian philosophers have proposed from a social-relational autonomy perspective to allow surrogacy contracts under certain circumstances - specifically, they suggest that legalization could be compatible with women's reproductive autonomy if it is done altruistically with protective measures and support for the surrogate's revocation of consent - I uphold that radical feminists properly make clear how oppression remains in the cultural environment that endorses surrogacy contracts. A macroscopic methodology, based on American philosopher Marilyn Frye's metaphor of the caged bird, is a helpful tool to comprehend why surrogacy contracts do not enhance women's reproductive autonomy, even if they enable some surrogate mothers to earn enough income to cope with economic pressures.

KEYWORDS: Wombs for rent, gestational surrogacy, reproductive freedom, reproductive autonomy, oppression. 


\section{INTRODUCCIÓN}

Pensar la llamada "gestación por sustitución» (GS, en adelante) amerita una consideración de la libertad reproductiva como una cuestión vital de profundo calado individual y colectivo. Lo anterior es válido, tanto por su impacto en la superación y emancipación de prejuicios y convenciones sociales, como por su papel en la democratización de la libertad sexual y de la planificación reproductiva. Rodeada de controversia, la GS consiste en que una mujer acepte llevar un embarazo con el propósito de ceder los derechos del bebé a las terceras personas que fungen como contratantes y promotoras de la transacción, la cual puede involucrar un pago o ser altruista. Se produce un embarazo no coital empleando técnicas de reproducción asistida (fecundación in vitro o inseminación artificial), sin que la mujer embarazada adquiera la obligación de ejercer la maternidad de la criatura gestada. Una fragmentación inicial entre maternidad y embarazo despierta pasiones morales a favor y en contra que merecen una prolongada revisión ética, especialmente por la imperante violencia y desigualdad en contra de las mujeres.

El objetivo del presente trabajo consiste en contrastar distintos posicionamientos sobre la libertad/ autonomía reproductiva, esperando arrojar mayor luz sobre la opresión sexual y su influencia en la autonomía y el autogobierno en los contratos de subrogación. Comienzo con una exposición del pensamiento del liberalismo reproductivo, que esgrime que esta práctica es necesaria porque regula los intereses de ciudadanas y ciudadanos persiguiendo una voluntad consciente e informada, siendo hipotéticamente libres de elegir caminos diferentes y poco entendidos socialmente para satisfacer intereses diversos (procreativos, económicos, empáticos). Prosigo con una revisión también liberal, pero que circunscribe la autonomía reproductiva con la realidad relacional de las mujeres. Continúo con una lectura feminista de lo privado y su factible vinculación con las actividades reproductivas. Desde esta perspectiva, la explotación de la capacidad gestacional es un rostro de la opresión manifiesta en el dominio de las decisiones reproductivas de las mujeres, que problematiza la agenda que defiende sus derechos. Quiero responder lo siguiente: ¿acaso la subrogación perpetúa relaciones nocivas e indeseables para la autonomía de las mujeres?, ¿estaríamos mejor sin estos contratos? ¿puede la GS significar resistencia ante la opresión, y no la asimilación de las herramientas del amo? (Lorde, 1984/2007: 110-113)

Por último, planteo que el feminismo radical conceptualiza críticamente la asimilación de los postulados a favor de contratar labores gestacionales (por dinero o altruismo). Primero, porque explica que la autonomía reproductiva es incompatible con acuerdos que transfieren un poder de acceso de terceros a funciones reproductivas adheridas al cuerpo. Segundo, porque sostiene que la elección individual coexiste con el patriarcado, que moldea la agencia personal femenina, siendo la toma de consciencia de esta influencia un proceso insustituible para ganar autonomía significativa ante las fuerzas opresoras. Me apoyo en la metáfora del ave enjaulada incapaz de fugarse del cautiverio, que conceptualiza la opresión sexual como una construcción social, discursiva y política macroscópica (Frye, 1983). Concluyo que el liberalismo reproductivo adeuda un análisis macroscópico que identifique el desbalance de poder entre las partes como una opresión reproducida por contrato. Sin desautorizar la agencia para conseguir fines valiosos para el florecimiento, se propone que despertar una consciencia de clase (sexual, social, racial, etc.) es fundamental para resistir la opresión y conservar la autonomía.

\section{EL LIBERALISMO REPRODUCTIVO Y LA SUBROGA- CIÓN DE ÚTERO}

Con la expresión liberalismo reproductivo ${ }^{1}$ se hace referencia al programa ético y moral que privilegia la elección individual en el ámbito de la reproducción humana; en congruencia con dicha primacía, las elecciones reproductivas son cercanas a la identidad personal y la noción del bien que produce felicidad y prosperidad (Robertson, 1994).

El liberalismo reproductivo se propone entender la decisión de tener hijos, o de no tenerlos, como libertades negativas. $Y$ lo mismo ocurre con la interrup-

1 Tomo prestado el término «liberalismo reproductivo», evidentemente crítico, de la feminista Janice Raymond (1995). Raymond denomina así a la corriente liberal que pone en primer lugar la elección y el concepto negativo de libertad para pensar el acceso a las tecnologías de reproducción asistida. Esto resulta inaceptable para Raymond porque la situación social de la mujer, todavía de coerción directa en muchos lugares del mundo, implica que muchas se hallen arrinconadas en roles de escaso poder para modificar sustancialmente su realidad. Que las mujeres padezcan esta desigualdad social se encuentra, en su opinión, en el centro de la reflexión ética sobre la utilización de las tecnologías de reproducción asistida y, muy especialmente, de la gestación subrogada. 
ción legal del embarazo, el uso de anticonceptivos y la impartición de una educación sexual y reproductiva científica y laica. En la actualidad, este liberalismo explora dilemas éticos como la modificación genética de nuestros descendientes para borrar o aminorar desventajas, enfermedades congénitas y algunas discapacidades. Igualmente, pugna en todo momento, por generar una actitud permisiva y abierta hacia a las técnicas de reproducción asistida (TRA, en adelante). La subrogación, desde este marco, plantea las mismas obligaciones por parte del Estado -mantenerse lo más aparte posible- que la reproducción tradicional, la inseminación artificial o la fecundación in vitro. Por lo tanto, la carga de la prueba corresponde al Estado, si es que se quiere restringir alguna de las técnicas mencionadas.

Un objetivo del liberalismo reproductivo es eliminar las interferencias que impiden a los usuarios el encuentro próspero con las tecnologías reproductivas y las personas colaboradoras (donantes de óvulo, madres subrogadas) que prestarán sus capacidades y partes corporales para que los primeros consigan sus fines (Robertson, 1994: 39). De manera análoga a una justicia distributiva económica, es deseable también una igualdad comparable entre las personas fértiles e infértiles, homosexuales o heterosexuales, o que padezcan dificultades estructurales para reproducirse. Encontrar una pareja fértil con voluntad y deseo de procrear se convierte en materia de deliberación y no de mera suerte, entre otras razones, cuando la ciencia y la tecnología impulsan los avances para alcanzar dicho florecimiento (Robertson, 2004). No todo el mundo procreará hijos biológicos en los cánones tradicionales; los avances científicos y los valores progresistas existen para ensanchar la autonomía reproductiva como derecho social y legal, una posibilidad para decidir y acceder a un panel de opciones que permitan fundar una familia (Alghrani y Harris, 2006).

Cabe señalar que las TRA y los contratos de subrogación suponen consecuencias difíciles de anticipar: los embarazos múltiples, daños en el aparato reproductivo femenino tras la extracción continua de óvulos para su donación o comercio, o la desestabilización de las definiciones de paternidad/maternidad. Las actividades riesgosas que involucran posibles desventajas para los agentes son, sin embargo, permisibles por la autonomía, salvaguardando así la parcela de soberanía inalienable para dirigir el timón de su existencia (Dworkin, 1972). La libertad procreativa posee, todavía, primacía sobre la inmensa mayoría de las objeciones paternalistas relacionadas con desventajas sociales, pues lo conflictivo orbita alrededor de regulaciones deficientes y manejadas por intereses mercantiles, pero no en las técnicas reproductivas ni en los riesgos aceptados para tal fin (Shalev, 1989; Robertson, 1995). Siguiendo este hilo, se aconseja permitir la subrogación no solo para ampliar las expectativas de reproducción biológica, sino también para abrir nuevas vinculaciones donde mujeres y hombres compartan sus cuerpos en beneficio mutuamente pactado, sea por samaritanismo, altruismo o dinero (Fabre, 2006).

Legalizar no equivale ni a la explotación masiva de mujeres ni a vender bebés por catálogo. A menudo, surge una relación denominada «explotación mutuamente ventajosa», en donde las partes obtienen un beneficio a partir de la carencia ajena sin dañar ni producir mayores desventajas que las anteriores (Wertheimer, 1992: 235-237; Robertson, 1994: 130132). El dilema de la explotación del cuerpo femenino, desde una metodología individualista, se resuelve mediante la colaboración voluntaria e informada sobre los riesgos, además de calibrando las ventajas y desventajas. Resulta más fructífero delimitar los bordes de una regulación aceptable, antes que calificar de abusiva toda la práctica; aún cuando la corrupción aceche y las agencias busquen aprovecharse de distintas vulnerabilidades, lo mismo ocurrirá si se prohíbe la práctica. Además, los padres intencionales también serían explotados si se desobedece el contrato, no solo las mujeres que gestan para terceros (Wilkinson, 2003: 9-27; Wilkinson, 2016: 142). Viviendo en un mundo laboral explotador, es prioritario distribuir más inteligentemente recursos y obligaciones conviviendo con esa imperfección, que abogar por medidas perfeccionistas que limiten la elección hasta un nivel inaceptable para las personas que necesiten de los cuerpos de las demás. Si las feministas quieren desligarse de lo biológico, sería congruente desvirtuar la maternidad gestacional como la opción moralmente más aceptable para favorecer la paternidad electiva (De Lora, 2019).

Las labores reproductivas son, por tanto, tipificadas como actividad productiva. Si empleamos manos, cuerpo e intelecto para escribir y pensar, al igual que para producir bienes, ¿cómo se justifica la excepción de las capacidades reproductivas? Se esgrime que dicha excepcionalidad tiene que ver con prejuicios y con un malestar cultural hacia todo lo que gira en torno a la sexualidad femenina, antes que por la efectiva 
protección de grupos oprimidos y de su situación económica (Nussbaum, 1999: 288-298). Siguiendo este planteamiento, la subrogación no comercia con seres humanos, sino que involucra el servicio corporal de un agente racional. La finalidad de los contratantes, o padres intencionales, es obtener los derechos parentales sobre la criatura gestada, y no desvirtuar la paternidad como una mercancía (Arneson, 1992; WiIkinson, 2016). Adquieren derechos parentales para cuidar y criar un bebé, no para adueñarse de un ser humano; contratan la capacidad de gestar, pero no la venta de la mujer completa. Si existiera un útero artificial o los trasplantes de útero fueran seguros para donantes y receptoras, la mayoría de las y los solicitantes perderían interés en la subrogación (Fabre, 2006: 187-190; Robertson, 2016). Para Lamm (2013: 47), los comitentes son la causa final del nacimiento, pues el embarazo no confiere a la gestante ninguna obligación o derecho sobre la criatura gestada, pues se transfieren esas obligaciones a terceros. La paternidad intencional es el hijo pródigo de la libertad negativa al fragmentar el embarazo y la maternidad para privilegiar el interés procreativo desde el inicio.

A donde quiero llegar es que, presumiendo la alienabilidad del cuerpo, se aduce que las capacidades para gestar y parir son recursos corporales materiales y que pueden transformarse en objetos de transacción y contrato precisamente para favorecer la autonomía, y no necesariamente en su detrimento. Entendida como disposición de las capacidades personales en beneficio propio, hay autonomía en ausencia de coerción o de algún tipo de enajenamiento que ponga a la persona por debajo del umbral mental y físico de sus capacidades racionales (Fabre, 2006). Sin embargo, las complejidades no acaban con la determinación del umbral y de las controversias fronterizas cuando la autonomía implica cierto poder sobre terceras personas. Para abonar tensiones, ninguna otra actividad genera vida nueva, una singularidad que merece una cautela equivalente. Por tanto, son necesarias herramientas conceptuales sobre la dinámica del cuerpo femenino y la capacidad gestacional en el contexto de la opresión sexista, la falta de oportunidades, la violencia machista, etcétera. Falta mayor inspección en la relación entre los agentes racionales y los mecanismos sociales, políticos y discursivos que encubren interacciones abusivas, explotadoras y subordinantes. La reproducción, sea coital o tecnológicamente asistida, es posible hasta ahora por la intervención de dos gametos sexuales diferentes y por una mujer capacitada para embarazarse. No obstante, el desbalance de los cuidados y su baja estima social son problemas que no han de desvincularse. Por este motivo, aproximaciones a la autonomía procreativa desde la perspectiva relacional proporcionan solidez a la discusión.

\section{LA AUTONOMÍA REPRODUCTIVA Y LA SUBROGA- CIÓN}

Las aristas de la autonomía no son comprendidas homogéneamente por el amplísimo espectro de liberales que, en diferente grado, abogan por permitir la subrogación de útero. Según la teoría de justicia planteada por Cécile Fabre (2006: 27-30), el respeto implica la obligación de abandonar intenciones paternalistas respecto de las decisiones individuales de las otras personas. La distancia del Estado respecto de las decisiones sexuales y reproductivas es una inmejorable demostración de democracia con justicia reproductiva. Para ello, el acceso a los cuerpos de las otras personas se convierte en derecho irrenunciable, consentimiento mutuo mediante. Nuestros cuerpos sirven para satisfacer intereses relacionados con una idea del bien próxima a la identidad, que nos conecta con los propósitos vitales. En la subrogación, el derecho contractual arregla las controversias ante la inexistencia de un hipotético derecho positivo para tener hijos. Así pues, el contrato cubriría los gastos de la madre subrogada, un seguro médico y una compensación por los riesgos; se pretende disminuir la explotación, entendida grosso modo como desbalance entre beneficios y esfuerzo dedicado a un trabajo, pero no como una condición intrínseca de la práctica (Fabre, 2006: 194-200; Straehle, 2015: 10)

Igualmente, John Harris (2001: 192-199) sostiene que la autonomía, idealizada en una infinitud sin oscilaciones ni claroscuros, comienza con la aceptación de pluralidad en las actitudes particulares sobre lo que es valioso. Las diferencias morales y axiológicas enriquecen la sociedad por la pluralidad. Existen, para ello, actitudes necesarias y complementarias para un auténtico respeto por los otros: un interés genuino por el bienestar ajeno y un respeto sin prejuicios por sus deseos, aún cuando no sean plenamente comprendidos. La libertad y la autonomía reproductiva requieren del respeto para existir. Por una parte, la reproducción es un área muy significativa de la vida por las decisiones que entraña, por lo cual cualquier idea de bienestar respetará que las decisiones reproductivas son fundamentales para la vida buena y el florecimiento. Por otra parte, los deseos están unidos a la idea de felicidad, y su único límite son los derechos de terce- 
ras personas a no sufrir daños. Bien encaminados, los deseos civilizan y permiten una exploración creativa de la vida que favorezca el avance moral y cultural. La autonomía no aspira a la perfección, y muchas decisiones han de tomarse en contextos poco favorecedores, o incluso de inmadurez psicológica y social. Se elige en función de quien se es, y debe evitarse una búsqueda excesiva del escenario idóneo para las decisiones relevantes.

Hay excepciones que afectan la autonomía: carencias en el raciocinio (incapacidad en la toma de decisiones y procuración del bienestar), dificultades serias para evaluar la información del ambiente, e incluso desacreditación de las decisiones por quienes nos rodean ${ }^{2}$. Una mujer que asimila los roles femeninos con excesiva conformidad, aceptando acríticamente la tradición, ve alterada significativamente su autonomía y el control de su vida, incluso si se reconoce como alguien feliz (Harris, 2001 :195-200). Específicamente sobre la subrogación, Harris cuestionó el pánico moral en torno a las transacciones en las que se incluye el útero y su función. Si otras partes del cuerpo son comerciables (todos usamos los brazos, piernas y cerebros para laborar), se pregunta: ¿por qué el útero no podría emplearse igualmente? ¿por qué mejor no entender el cuerpo humano como un todo igual sin conferir mayores preocupaciones por el útero? (Harris, 2001: 144). El filósofo inglés duda que ciertas partes del cuerpo sean más especiales que otras para la conservación de la dignidad humana. Retomaré esta idea más adelante.

No obstante, gracias al giro crítico del individualismo posesivo, sobre todo desde enfoques feministas (Shanley, 1993; Pateman, 2002), el énfasis en el estudio de la autonomía recae en los contextos sociales y su influencia en la estructuración de las decisiones reproductivas, desautorizando el protagonismo de fenómenos psicológicos solipsistas. Las opciones reproductivas no se deben a un agente racional emancipado gracias únicamente al estado de derecho. Al dimensionar el influjo socio-relacional en la agencia y la capacidad de proveerse de los recursos para vivir li- bremente, surgen matices precisos para una discusión apropiada de la subrogación.

Siendo numerosas las aristas que intervienen en la autonomía, hace falta conceptualizarlas para alejarse de concepciones individualistas. Marina Oshana (1998) define la autonomía relacional alejándose del psicologismo y, particularmente, discrepa en que la capacidad de decidir sea una evidencia suficiente y definitiva de autogobierno. Por el contrario, Oshana aboga por su constitución relacional, sobre todo por la construcción de opciones relevantes en un entorno que permita su ejecución, y no solo uno que no interfiera o que se conforme con brindar derechos negativos. La autonomía relacional es un concepto racimo que abarca: la reflexión e identificación con sus objetivos como bienes morales y la implicación de terceros y del entorno en sus acciones y motivaciones; la independencia de entornos dictatoriales y unívocos; el acceso a opciones relevantes, entre las cuales se aprecia sobre todo la diversidad y riqueza para sí y no para servir exclusivamente a otros; y pertenencia a relaciones sociales seguras que respalden las opciones, incluso si son discrepantes con las visiones de las mayorías ${ }^{3}$. Por lo anterior, se posee autonomía cuando se vive, se desarrolla y se interactúa en relaciones interpersonales sin mecanismos coercitivos, con reconocimiento de sus capacidades racionales humanas. O bien, si se presentan opresiones, la autonomía confiere capacidad de reflexionar sobre el rol del entorno opresivo en sus limitaciones personales, comprendiendo la complejidad de las interacciones y su situación particular. Sobre las mujeres y los roles de género asociados al sexo, lo relevante históricamente hablando sobre la falta de autonomía, muchas veces provocada por los estereotipos, es el patrón de prácticas sociales que las educan en la sumisión, en lugar de reconocerles soberanía y libertad como derechos humanos básicos. Una autonomía deficiente tiene que ver con relaciones personales nocivas y opresoras, e instituciones sociales que forman, educan y perpetúan la subordinación (Oshana, 1998: 90-96).

2 Pensemos en el fenómeno denominado gaslighting, cuando el agresor desafía las percepciones y experiencias de la víctima, empleando la persuasión o complicidades, con el objetivo de disminuir la autonomía de la segunda, y así continuar con la manipulación a un grado mayor.

3 A pesar de que las oportunidades profesionales y laborales son distribuidas más equitativamente y los prejuicios son denunciados como discriminativos, muchas mujeres no siempre perciben ciertas oportunidades como opciones de vida factibles y realizables debido, sobre todo, a la introyección de roles de género nocivos. Entonces, los estereotipos de género funcionan como restricciones socioculturales o biográficas, que limitan la libertad personal. Véase: Álvarez Medina, Silvina (13 de diciembre del 2012). La autonomía personal de las mujeres. Una aproximación a la autonomía relacional y la construcción de las opciones. Seminario de la Facultad de Derecho de la Universidad de Palermo [en línea]. Córdoba, Argentina: Universidad de Palermo, pp. 1-25, Dir. URL www.palermo.edu/derecho/pdf/La-autonomia-de-las-mujeres.pdf [Fecha de consulta: 27 de octubre del 2021]. 
Ampliando esta línea, Silvina Álvarez-Medina (2017) hace hincapié en que la autonomía personal se opone a la tiranía, configurando un escenario en el que sea posible responder a modelos de dominación contrarios a la decisión personal. Siguiendo a Oshana, la autonomía es la racionalidad práctica que permite relaciones libres y recíprocas con las demás personas, a la vez que confiere la reflexión en el destino y los objetivos valorados como buenos e inaplazables. Sin pretensión alguna de ser un átomo individualizado que se defiende de interferencias todo el tiempo, la autonomía favorece una posición activa ante un ecosistema plural y diverso para conservar su identidad (Álvarez-Medina, 2017: 149-153). Configurar y ejercer los derechos reproductivos relacionalmente significa atender las asimetrías relevantes entre hombres y mujeres, en tanto que sus vidas son singulares por sus cuerpos con distintas capacidades reproductivas. La protección jurídica debe considerar, por tanto, esas diferencias y la existencia del patriarcado para contribuir a que los estereotipos dejen de extenderse. Máxime cuando las opciones y decisiones reproductivas de las mujeres se organizan y ejercen, pues, en escenarios complicados que a menudo forjan sus preferencias. En este contexto, los derechos reproductivos operan como un discurso normativo encaminado a la construcción de relaciones respetuosas favorecedoras de la autonomía reproductiva y de la intimidad como fuerzas creativas más relevantes que el daño ocasionado por las asimetrías (Álvarez Medina, 2017: 154-167).

¿Qué aporta el marco de la autonomía relacional al problema presente? Mary Shanley (1993 y 2002) formula que la subrogación es apenas permisible, siempre y cuando la mujer mantenga la opción de reclamar los derechos maternales sobre la criatura hasta, incluso, tiempo después del nacimiento. La revocación del consentimiento se justifica por la complejidad de las experiencias gestacionales y, sobre todo, por la inalienabilidad de la libertad como derecho fundamental, en atención a lo establecido por John Stuart Mill en su argumento sobre la imposibilidad de venderse uno como esclavo. El embarazo y el parto no son análogos a ningún trabajo (Shanley, 2002: 109), por el tipo de experiencias corporales sobrecogedoras que traen consigo, y porque ninguna otra actividad humana, voluntaria o no, produce vida nueva. En el embarazo, feto y mujer están interrelacionados hasta el nacimiento en un solo hábitat corporal. Emociones, energías y pensamientos que conforman el yo de la mujer se unen en coordinación participativa en el em- barazo. Por tal motivo, la mayoría de las mujeres valoran la gestación en mayor medida que el componente genético, mientras que la mayoría de los varones se inclinan fuertemente por el segundo (Shanley, 2002: 114). Permitir la subrogación comercial legitima que hombres y mujeres solventes compren mujeres de clase trabajadora, o pertenecientes a grupos étnicos desfavorecidos. Oponerse a que una madre gestante desista de continuar con el pacto y entregar al bebé comparte un aire de familia con actitudes conservadoras contrarias al divorcio, que obligan a los cónyuges a mantener una promesa de vivir juntos hasta que la muerte los separe. Se ignora así que revocar una decisión previene daños al yo como ser relacional (Shanley, 1993: 630; Shanley, 2002: 116). La autonomía consiste también en la deliberación reflexiva, incluyendo la renuncia al cumplimiento de una promesa o contrato. Poner a las mujeres en el centro implica ir más allá de la libertad como facultad para pactar contratos, y defender un futuro donde prevalezca la autonomía.

Martha Field (1990) comparte con Shanley (1993) que el cambio de decisión sobre los derechos parentales es una política aceptable para la autonomía de la mujer; además, se desincentivaría el acceso a una práctica riesgosa en su faceta comercial, máxime si es abierta al turismo nacional y extranjero. Repensando los vínculos sociales y la mercantilización, Debra Satz (2010) define que algunos mercados son nocivos por las asimetrías en status y por la agencia débil de muchas personas. Respecto de la subrogación (comercial o altruista), afirma que nada hay intrínsecamente malo en ella; lo problemático son las externalidades: la vulnerabilidad, la autonomía débil, la desigualdad de género y la falta de poder. La posición ética ante un mercado nocivo no es prohibirlo, sino procurar que las obligaciones y responsabilidades atenúen las externalidades (las desigualdades provocadas por las lógicas del mercado) y así fortalecer a las partes más vulnerables (Phillips, 2013). Esa regulación pasa por garantizar un consentimiento de calidad en países donde, legalmente, los derechos reproductivos negativos de las mujeres sean ampliamente defendidos por encima de los intereses invasivos de terceros. Incluso ejerciendo un derecho positivo generado por una libertad reproductiva, los contratantes no deben beneficiarse de explotaciones originadas por la ancestral negación de derechos negativos que sufren muchas mujeres del mundo subdesarrollado, como en India, que las deja sin posición política para defenderse de abusos. En el mundo desarrollado, mujeres 
con mayor poder ofrecen servicios reproductivos sin mayor problema. Lo importante es que los derechos positivos perderían fuerza normativa si son utilizados para aumentar la ventaja de los privilegiados respecto de las mujeres más vulnerables del mundo; la comercialización reproductiva debería, por tanto, focalizarse en la emancipación de las segundas (Panitch, 2013).

Desarrollar una autonomía reproductiva y garantizar un consentimiento de alta calidad son conquistas mayúsculas: libertad política, derecho de privacidad y ciudadanía democrática plena (Dworkin, 1993: 51). Sin embargo, la prevalencia del criterio unívoco del binomio elección-consentimiento pierde de vista el retrato general de interacciones desiguales, enmarcándonos en la división de esferas en pública y privada que, además, no rastrea los antecedentes que perfilan el consentimiento de una persona oprimida. La hipotética libertad universal acaba siendo asimétrica por el desequilibrio de poder público según el sexo, por las ficciones cosificadoras del cuerpo y por el dominio de la visión atomista de la autonomía en la academia. Esas razones convencen a las feministas radicales de que sus reparos sobre la neutralidad y la justicia liberal son justificados.

\section{LA ELECCIÓN AUTÓNOMA DE GESTAR PARA TER- CEROS Y LA DICOTOMÍA PÚBLICO-PRIVADO: LA RÉPLICA DEL FEMINISMO RADICAL}

El feminismo radical antepone la liberación de las mujeres frente a las promesas progresistas de la técnica encarnadas en la subrogación, entre otras alternativas procreativas. Estas feministas refutan que la presunta privacidad de la sexualidad, la reproducción o el amor constituya una política inofensiva. Por el contrario, a través del análisis sistemático de experiencias íntimas, han reconocido y conceptualizado los privilegios que la dicotomía público-privado otorga a los hombres. Paralelamente, han desvelado las desventajas históricas que siguen padeciendo las mujeres en todas las esferas de la vida. Con la consigna lo personal es político, los desencuentros éticos con el liberalismo reproductivo alcanzan prominencia notable (Hanisch, 1969/2000).

En este sentido, que una práctica que instrumentaliza el cuerpo femenino ocupe la atención del movimiento, es un distractor para la agenda feminista. Su legalización conforma una agenda sobrevenida, contraria a los objetivos de emancipación de las mujeres que no encontrará cobijo en nombre de la libertad (Valcárcel, 2017). Anteriormente, el liberalismo progresista se ha inclinado a normalizar prácticas sexuales y reproductivas persiguiendo una protección a la decisión individual, entrando así en un enfrentamiento teórico y político con este feminismo que interpreta esa avanzada como misoginia institucional (Dworkin, 1985: 174; Leidholdt y Raymond, 1990). La aprobación de la prostitución y la pornografía en clave emancipadora, confiando en que la agencia aumente las capacidades de obrar en libertad, concede principio de autonomía a muchas mujeres violentadas y oprimidas, minimizando la desigualdad estructural y el silenciamiento de las industrias, los consumidores y las mafias. Todo esto erosiona paulatinamente la lucha colectiva que busca abolir la explotación sexual; cuando la libertad de expresión y los derechos laborales son discursivamente empleados en defensa de dicha explotación, se neutralizan tanto la práctica feminista como los cuestionamientos hechos al Estado sobre su implicación en la violencia sexista (MacKinnon, 1990: 1-13).

Para la crítica feminista del liberalismo, la dicotomía público-privado es una pata del patriarcado moderno (Pateman, 1989: 118-136). Según Celia Amorós (1987), el espacio público es el ágora del poder, congrega la visibilidad social, el principio de individuación y la ciudadanía. El contrato social ilustrado otorgó los mismos derechos a todos los ciudadanos varones en un pacto realizado en un espacio entre iguales, interclasista, usurpador de lo genéricamente humano. Las vidas de las mujeres fueron vaciadas del interés que merecen los acontecimientos característicamente humanos. El trabajo, el comercio, el gobierno y la educación se institucionalizaron de la mano de la jerarquía masculina. Por el contrario, el espacio privado (atinadamente acuñado por Amorós como el espacio de las idénticas, inspirada por la ley de identidad de los indiscernibles de Leibniz) se define como la arena sin público, donde la similitud de propiedades cualitativas entre sus integrantes las convierte en idénticas entre sí. La indiscernibilidad es su sello característico; son todas «idénticas» e indiferenciadas por la privacidad de sus actividades.

¿Es significativa la identidad de la madre gestante si los contratantes aportan tanto la intención creativa como la carga genética? De ahí que importe la indiscernibilidad, pues al no existir nada en cuanto a prestigio o reconocimiento que repartir, tampoco hay razón suficiente para postular la discernibilidad de talentos, capacidades, florecimiento del intelecto. Por eso, el espacio privado desaparece de la escritura 
de la historia, las actividades domésticas carecen de parámetros que midan su valor social y potencial revolucionario. El embarazo, el nacimiento, la lactancia, la sexualidad, los cuidados, la crianza de la niñez, el trabajo del hogar, etcétera. Las actividades atribuidas a la feminidad fueron enclaustradas pese a su relevancia. Se trata, pues, de la jerarquización ideológica de los espacios, y el espacio de las idénticas es poco propicio para la individuación (Amorós, 1987; Hanmer, 1987; Shanley, 1993). El acceso al trabajo asalariado de las mujeres fue, muchas veces, en oficios identificados con estereotipos: enfermeras, secretarias, maestras de educación preescolar, costureras, limpiadoras, camareras. Costó tiempo, lucha y evolución social cambiar esas reglas y transformar la realidad que concediera mayores oportunidades laborales, y así conseguir la emancipación profesional y sindical, denunciando la dependencia del salario familiar. (Pateman, 1989 [1980]: 131-134). Sin embargo, la gestación sigue siendo percibida como labor corporal, sin individualidad, se niega que el embarazo implique una labor mental compleja por medio de la cual la mujer imprime su singularidad creativa. Ello obliga a que las decisiones sexuales y reproductivas, como opciones prominentes, sean analizadas bajo ese prisma, incluso si hay consentimiento.

¿Qué sobrevive de este resabio? Primero, que la reproducción humana (las TRA, la subrogación e incluso el coito de toda la vida) como experiencia social se sigue tipificando, ideológicamente, en el espacio privado; el menor poder público de las mujeres es la piedra angular que explica dicha estratificación. El sexismo, como ideología biologista, tergiversa la ontología de las mujeres en su capacidad para conducirse racional, autónoma y relacionalmente. Amorós (1987) destacó que la no-individuación sigue la pauta de un biologismo que aproxima una presumible ontología femenina más a la naturaleza que a la cultura, creando una dicotomía ficticia, pero ideológicamente poderosa. Los destinos impuestos se fundamentan en que el rol reproductivo determina también las vidas políticas. No quiero decir que las actividades reproductivas carezcan de complejidad cognitiva y emocional a la altura de trabajos más valorados, y de visibilidad pública. Todo lo contrario: las labores reproductivas son avanzadas y han sido (y siguen siendo) despojadas de su carácter político por la ideología patriarcal para borrar la participación pública de muchas mujeres; se niega de este modo cómo sus realidades contribuyeron a los mejores logros civilizatorios, ilustrados y modernos. Es pertinente, pues, proponer que la gestación por sustitución (término que condensa la mutua indiferencia entre embarazo y maternidad, previo pacto) proviene de una sociedad patriarcal que privilegia lo que piensan, hacen y sienten los varones incapaces de gestar y parir. Las mujeres son individuos de derecho cuando el contrato de GS especifica que son propietarias de los úteros que, pública y voluntariamente, ponen a disposición de terceros (Pateman, 1988: 216)

Sobre la subrogación uterina, el feminismo radical explica que se impide la toma de consciencia sobre la opresión (y la construcción de un nuevo conocimiento sobre la resistencia corporal y afectiva) mediante la pérdida del control sobre su cuerpo y la dominación de las capacidades reproductivas a través de tecnologías y de una ingeniería política cargada de misoginia (Hanmer, 1987: 88-104). Conectemos, pues, dos cuestiones que explican la incompatibilidad de la subrogación con una agenda liberacionista: 1) Por la pérdida de la autonomía reproductiva por un embarazo controlado por contratantes; y 2) Por la historia viva de explotación sexual/reproductiva, exacerbada por la interseccionalidad de otros modelos de opresión, como la clase social, el racismo, la lesbofobia o la xenofobia. A continuación, profundizaré en dicha postura, y en su congruencia para contrastar las posturas expuestas en otros apartados. ${ }^{4}$

\section{LA OPRESIÓN, LA AUTONOMÍA SEXUAL/REPRO- DUCTIVA Y LA INCONFORMIDAD FEMINISTA FREN- TE A LA SUBROGACIÓN}

La pertinencia del feminismo radical descansa en el entendimiento de los roles sociales y contractuales (esposas, madres, prostitutas, gestantes) como facilitadores y pilares de un sistema opresor supremacista

4 Es común que se replique, si las mujeres consienten gestar para otros y sus emociones benefician la consideración que tienen de ellas, cualquier objeción sobre la práctica es paternalista. En estudios etnográficos cada vez más comunes, las mujeres gestantes son descritas como figuras activas y creadoras de vínculos; la alegría, el altruismo, pero también el incentivo económico, forman parte de una nueva red de trabajo reproductivo en la cual se disgregan los roles maternales según la aportación en la producción de un nuevo bebé: madre intencional, genética, gestacional, etcétera. La instrumentalización del trabajo emocional y afectivo en beneficio de terceros, es descrito como un recurso fungible que se aporta a una cadena reproductiva (Ragoné, 1997; Smietana, 2017; Olavarría, 2018). Vale, entonces, preguntarse por el desnivel significativo entre la madre gestante y las otras partes (es ella la parte más invadida), sobre todo en la transferencia de su derecho a cambiar de parecer, de ceder irrevocablemente los derechos maternales sobre la criatura gestada. 
masculino que adormece la independencia y la autonomía de las mujeres. Se enaltece el sacrificio en nombre del culto a lo masculino. La opresión se adscribe según la pertenencia a una clase, o a varias, subyugadas al poder de otros grupos o clases con mayor voz, poder y representación pública e histórica, y no por una injusticia distributiva. Personas negras, indígenas, inmigrantes; mujeres lesbianas/heterosexuales; hombres gais; personas pertenecientes a la clase trabajadora, o con discapacidades relevantes, experimentan todas opresiones con diferentes manifestaciones sociales. La opresión actúa como un concepto-racimo con varios rostros: explotación, marginación, violencia, falta de poder, sometimiento a un imperialismo (Young, 1990). Según Marylin Frye (1983), la opresión sexual de las mujeres es fruto de la falta de libertad y autogobierno provocada por una historia material de dominación masculina por el hecho de haber nacido mujeres. Dicha opresión se perpetúa cuando las normas, costumbres y relaciones sociales se interrelacionan para detener u obstaculizar a las mujeres cuando proceden humanamente hacia su libertad. Opresión es cuando no hay otra salida diferente a toparse una y otra vez, de mil y una formas, con límites al desenvolvimiento de la personalidad. El sexo biológico no determina ni la tiranía ni la esclavitud, pero la simbología tejida a su alrededor fabrica auto-percepciones en las mujeres, útiles para quienes ostentan el poder (Frye, 1983:15-17).

La opresión específica por nacer sexuadas como mujeres (multiplicada si suman otras opresiones) puede representarse como si fueran aves enjauladas, siguiendo la metáfora de Frye, que introduce dos aproximaciones de la realidad: una microscópica y otra macroscópica. La primera concentrada en abordar interacciones entre agentes e interferencias, no comienza por afirmar que la jaula es una cárcel. Prioriza el efecto de cada barrote por separado que, individualmente, interfiere en el ave cuando intenta escapar. La segunda analiza todos los barrotes que conforman la jaula en conjunto, para mostrar que el interés de que permanezca el ave en cautiverio es, estructuralmente, masculino.

El análisis microscópico propone enunciados particulares y aislados que combaten la opresión como si fuese un desajuste en la distribución de oportunidades que puede arreglarse atacando la discriminación. Efectivamente, atendiendo problemáticas particulares es posible que la balanza se incline más a favor de la persona oprimida, sin llegar a proponer la trans- formación del tejido social para el cual dicha elección funciona de una manera y no de otra.

Por el contrario, el análisis macroscópico desconfía que la mentalidad individual y sus manifestaciones sean un método apropiado para definir qué es opresión y qué no lo es. Más bien investiga la interacción entre las acciones de los actores y las instituciones; el poder y las barreras que separan a los opresores de las oprimidas. La jaula confunde al ave encerrada, que moviéndose de un lado para otro solamente ve un barrote al frente y piensa que, aleteando, logrará escurrirse por los espacios que los separan. Cuando se afirma que las mujeres son oprimidas por su sexo (capacidad reproductiva incluida), los efectos se reproducen en todas las actividades, sin importar si corresponden a la esfera pública o a la privada. La línea que las separa es meramente nominativa. Un contrato que vende la gestación amerita, entonces, un análisis macroscópico.

Volvamos brevemente con John Harris (2001) y las dificultades de la autonomía anteriormente explicadas. El filósofo afirmó que crecer en un entorno adverso al desarrollo personal es dañino para la autonomía. A diferencia de los hombres, para las mujeres crecer en el patriarcado ha significado el silenciamiento de abusos sexuales, feminicidios, cosificación, violencia sexual y de pareja, asimilación de estereotipos durante la conformación de la identidad en la infancia y adolescencia. Por ese motivo, pensar entonces que el útero es como cualquier órgano es despolitizar el cuerpo de la mujer. Igualmente, suponer que las objeciones hacia la instrumentalización del útero descansan en el pánico moral y no en una lectura crítica del poder es desconocer los debates feministas. La concepción de Harris sobre el cuerpo es la de un recurso para concretar intereses, y no una entidad especial, revestida de dignidad y de una fuerza política. Se desprende de esta visión que ciertos servicios corporales no atentan contra la dignidad humana ni tampoco son intrínsecamente abusivos. Sin embargo, de continuar este hilo, se corre el riesgo real de dejar intactas estructuras de dominación y sujeción sexual que operan, con ahínco, sobre los cuerpos de las mujeres. Así, el planteamiento de que la elección de gestar para terceros (y la renuncia de cualquier derecho a posteriori) está libre de relaciones opresivas si hay consentimiento informado, ejemplifica una visión microscópica que prescinde de la historia de aprovechamiento y explotación por los varones y por todo sistema económico ejecutado hasta hoy de la actividad reproductiva femenina. 
Pensar y diagnosticar la opresión macroscópicamente requiere identificar las relaciones de dominación entre los opresores y los oprimidos en un tiempo determinado; esto implica tomar consciencia colectiva del impacto de esa relación en la capacidad que hoy tienen las mujeres para decidir libremente. Gerda Lerner (1986) sitúa el origen del patriarcado en una jerarquía sexual construida socialmente por hombres y mujeres, pero que oprime a y se nutre de las segundas. En la alborada de las primeras civilizaciones humanas, el tráfico de mujeres entre organizaciones tribales derivó en acuerdos para intercambiar el bien más preciado: el cuerpo sexual y reproductivo que provee a las familias de status, prosperidad y continuidad. De hecho, quedan roles sociales persistentes hasta hoy que conservan un aire de familia con los intercambios pactados de cuerpos femeninos trabajadores. Lerner hilvana que los roles sociales de las mujeres (el matrimonio, la prostitución y la servidumbre sexual, la explotación doméstica) conforman la permanencia del gobierno de los hombres a costa de los cuidados exclusivamente dados por las mujeres. Ellas también construyeron las civilizaciones, aportaron avances científicos y forjaron la economía comunitaria y global. Sus expresiones están vivas en la cultura y el pensamiento humanístico no sería el mismo sin sus ideas. Sin embargo, la mayoría de las teorías políticas y filosóficas modernas negaron que la opresión de la mujer fuese un cuestionamiento medular a la dicotomía público-privado. Pero el despertar de la conciencia feminista sobre la experiencia vivida, y su resistencia política como forma de acceso al conocimiento, es posible por el reconocimiento del pasado de las mujeres. La escritura de su historia y su conexión con un futuro alternativo alejado del patriarcado modifican la definición de la autonomía de la mujer en función de los objetivos y estrategias para transformar sus vidas (Lerner, 1986: 228-230; Lerner,1993: 274-283; MacKinnon, 1989: 83-85).

En la sociedad patriarcal, los hombres adquieren poder sobre las mujeres; por el contrario, como casta oprimida, las segundas carecen de un poder similar, no tienen un acceso comparable ni al poder ni a las vidas de los otros. Esta disposición entera de las mujeres fue el primer boceto de una cruel institución basada en la propiedad de otras personas como si fueran objetos: la esclavitud. No obstante, la liberación es posible; si el patriarcado fuera eterno, ¿cómo se explica el despertar de consciencia de tantas mujeres en los últimos siglos? La historia debe explicarse desde una perspectiva todavía pendiente que enfatice que el patriarcado exige a las mujeres dedicación mental y falta de consciencia de clase para mantener en pie las instituciones que, social e históricamente, las excluyen. La opresión patriarcal se perpetúa cuando falta lucidez para observar la nocividad de ciertas prácticas no recíprocas basadas en la misoginia, especialmente la satisfacción de los intereses masculinos (Lerner, 1986: 232; Lerner, 1993: 274). El cambio es redirigir las energías vitales e intelectuales, así como la creatividad y el trabajo emocional, para cultivar un conocimiento entre mujeres que ponga un freno a los intereses extractivistas de sus opresores. La resistencia es reconocer sus historias y estrategias colectivas de libertad; reorientar la atención es reorientar las pasiones hacia otras mujeres (Frye, 1983: 171-172).

Supongamos que el análisis macroscópico minusvalora decisiones que, aunque poco emancipadoras, transforman significativamente un contexto desfavorable por otro más cómodo, lo cual otorga a un agente un mayor margen de negociación con el entorno. Esto es, cuando un agente elige una alternativa aparentemente poco atractiva, pero que resuelve una problemática a nivel individual a corto plazo. Entonces, el agente percibe con indiferencia otras alternativas más ambiciosas que buscan transformar los desiguales flujos de poder desde una perspectiva macrosocial y estructural, pues le bastó con una respuesta inmediata para su particular situación. ¿Qué tal si el dinero recibido por la madre gestante es inasequible de otra manera y si, después del pago, adquiere ventajas para proteger sus intereses? Como respuesta a esta cuestión, conviene distinguir entre los beneficios de un ingreso económico oportuno y la desventaja sistemática de una clase que, con menos opciones, se inclina a esas labores. También las elecciones, algunas aparentemente triviales, son realizadas en relación con la opresión de un grupo determinado, en coexistencia con grados fluctuantes de libertad. El sometimiento surte efecto por reafirmarse diariamente, sin descanso, en un tira y afloja constante en el que el sujeto oprimido experimenta una libertad parcial, pero en una dinámica de sujeción constante. Las decisiones oxigenan la autonomía, pero nunca será lo mismo decidir sin consciencia de la opresión y de sus múltiples y complejas transformaciones que decidir en resistencia política, con esa consciencia. Sólo así es posible distinguir que la opresión influye poderosamente en las oportunidades accesibles y promovidas por el statu quo (Frye, 1983: 54-57).

Visto lo anterior, ¿qué hay de malo en la subrogación? ¿Podemos decir que hay autonomía relacional 
en un contrato de esta guisa? Las jerarquías sexuales y de clase social entre madre gestante, contratantes e intermediarios producen una relación asimétrica con obligaciones desproporcionadas. Si con la excusa del eslogan "este cuerpo es mío» permitimos un mercado de subrogación de útero, se precipita la ficción de la propiedad del cuerpo sin reflexionar que, los derechos reproductivos en cuestión, no son respetuosamente tratados por lógicas mercantiles que regulan la adquisición de cosas. Tales derechos se refieren a un control de la vida y las experiencias autónomamente aceptables (Beltrán, 2017). Cuando se vende la gestación, formalizando así la adquisición de bebés a la carta, los derechos de maternidad son desvinculados del embarazo por la autoridad de algunos y transforman, las normas de las relaciones de cuidado en códigos para efectuar transacciones. Por la precariedad, la brecha salarial, y la persistente división sexual del trabajo, especialmente en regiones subdesarrolladas, el poder para inaugurar mercados convierte, efectivamente, las capacidades reproductivas adheridas al cuerpo en objetos a disposición de terceros poderosos (Anderson, 1995: 142). Y aunque todas y todos compartamos los mismos derechos, precisamente por la diferencia sexo-reproductiva, no deben desconocerse las diferencias relevantes en experiencias corporales que generan los subsecuentes derechos. El contrato crea una ficción política ahora denominada prestación de útero, cuando en realidad es la energía vital/emocional/mental de la mujer la que se vende como materia alienable y explotable (Pateman, 1988: 211-221; Dickenson, 2017: 74-83).

Sabemos que maternidad y gestación no son sinónimos: existen madres adoptivas, de crianza, madres lesbianas no gestantes que aportan su óvulo. En la subrogación, se afirma el poder de efectuar un embarazo según la voluntad de quien ostenta autoridad legal y social, pero no el de la mujer. ¿Qué autoriza la autodeterminación de los contratantes como padres intencionales? Además de la libertad negativa, es mejor preguntarse por qué algunas intenciones transforman la realidad empleando contratos, mientras otras convicciones son erosionadas, sin importar la licitud de sus demandas, por oponerse a una autoridad que excede sus límites (Torres-Quiroga, 2019). La maternidad gestacional es reemplazada por la voluntad creativa de los patriarcas que extraen la energía de la mujer para convertirla en un regalo (Pateman, 1988: 214).

¿Cuál es la aportación del feminismo radical a este debate? Sin duda su insistencia en mostrar que la autonomía sexual y reproductiva de las mujeres, en contraposición a la de los varones, se inscribe en una resistencia política multidimensional que cuestiona la ficción de la igualdad. Por ejemplo, señalan que los hombres ganan privilegios mediante la cosificación de los cuerpos de las mujeres, hecho presente en la subrogación independientemente de su status legal. La subrogación legitima un trato indigno; convierte a las mujeres en cuerpos proveedores de bienes y recursos mientras acentúa sus desventajas para desarrollar una autonomía, favoreciendo un clima social sexista poco proclive para las decisiones libres. El mercado reproductivo recrea una cultura industrial que cosifica el útero, convirtiendo este contrato en un pináculo de la glorificación de roles subordinantes (Berkhout, 2008; Patrone, 2018). Y, además, según destaca Janice Raymond (1990b), la elección de gestar para otros se comprende, relacionalmente, al estudiar el poder atribuido a los roles sociales de la feminidad en su totalidad. Ninguna metáfora sobre la GS es trivial, particularmente cuando el altruismo y la donación de la capacidad de gestar son empleadas como estrategias discursivas para constatar la separación tajante entre el cuerpo reproductivo y la mujer racional con dignidad porque hay intereses contractuales que satisfacer. Por otra parte, no se puede hablar del altruismo en abstracto, pues éste se practica en relaciones sociales susceptibles de reproducir estereotipos de género que niegan la autoafirmación de las mujeres (Raymond, 1995). De ninguna manera el feminismo radical afirma que las mujeres sean eternas víctimas pasivas necesitadas de tutela y paternalismo; éste no niega la agencia y la autonomía en contextos de múltiples opresiones, sino que las conceptualiza como resistencia individual y colectiva frente a la dominación, y no como asimilación estratégica de los hipotéticos beneficios que traen ciertos estándares sexistas (Raymond, 1990a: 109-110).

\section{IDEAS FINALES}

Es pertinente pensar la libertad y la autonomía reproductiva considerando la óptica planteada por el feminismo radical, que añade conceptos ausentes en el liberalismo reproductivo más clásico, y que no se presentan así en la perspectiva de la autonomía relacional vinculada al feminismo liberal. Así como el masculino genérico del castellano borra a las mujeres igualmente, una definición neutral de libertad reproductiva, ignora que la opresión sexual y reproductiva produce asimetrías significativas. Establecer analogías entre la maternidad, la gestación y el parto (entre 
otras manifestaciones corporales) con cualquier otra actividad, es vaciar una experiencia vital sin parangón, desestimando sus vindicaciones políticas.

Se plantea, además, que el despertar de la consciencia feminista ensambla las violencias cotidianas y la opresión sistemática como parte de un todo: es una actividad reflexiva de la autonomía. La pregunta entonces, es si la autonomía persiste en contextos de opresión sistemática o no. Para el feminismo radical es una creación relacional producto de la resistencia política, colectiva, que precisa de (auto)afirmación individual. La autonomía sexual y reproductiva florecerá según aumente el distanciamiento respecto de los intereses económicos e ideológicos del patriarcado, que presenta como oficios, trabajos o roles deseables de las mujeres, la prostitución, la maternidad tradicional, la pornografía, el matrimonio, la heterosexualidad obligatoria (Rich, 1980) o la subrogación de útero.

Además, el feminismo radical insiste en rescatar que la autonomía de la mujer implica una capacidad para identificar los mecanismos de los agentes opresores para seguirse beneficiando del cuerpo femenino, incluyendo actividades relacionadas con la sexualidad y las capacidades reproductivas. Andrea Dworkin sostuvo que emprender acciones precisas (legales, pero no exclusivamente) contra los mercados sexuales y reproductivos es proteger la integridad corporal y la fuerza vital de las mujeres, un derecho civil irrenunciable a la par que la libertad de expresión (Evans, 1991). Como argumenta Scott Anderson (2002: 777-780), prohibir el consumo de prostitución es justificable, en atención de las mujeres prostituidas, porque su normalización implica que algunas personas carezcan de poderes específicos para impedir abusos y violencia sexual, capacidades claramente vitales para la autonomía. Las relaciones sexuales son intrínsecamente sociales, y encajan en una miríada de jerarquías simbólicas cuyas fronteras marcan la diferencia entre quienes compran y quienes venden el cuerpo sexual/reproductivo/cuidador. Legalizar la prostitución contradice que la autonomía sexual es un derecho que posibilita el ejercicio de libertades conectadas a convicciones íntimas y emancipadoras. Asimismo, se toleraría que una determinada clase de personas experimente mayores presiones para vender el control corporal por sus carencias económicas, falta de oportunidades, o por (sobre)vivir en violencia constante. Ciertas leyes (como el modelo abolicionista nórdico) son capaces de conectar la protección de la autonomía sexual con un despertar de consciencia social que exponga que la prostitución autoriza a los hombres a defender que sus deseos e intereses sexuales introduzcan riesgos mayores en la autonomía sexual de mujeres especialmente marginadas. Algunas puntualizaciones útiles para construir una postura crítica de la prostitución son: 1) dado que la falta de poder es mayor en mujeres oprimidas además por su clase social, raza y origen, son ellas las que se verían más forzadas a remover las barreras que separan la intimidad sexual del comercio; 2) la autonomía sexual/ reproductiva está ligada a la autonomía política y la libertad de expresión; no hay separaciones tajantes entre ellas, sino interdependencia; 3 ) incluso si hay mejoría económica normalizando la prostitución, es improbable que su legalidad transforme positivamente el problema macro de la subordinación económica y social de las mujeres (Anderson, 2002: 764-778).

En la subrogación ocurre una denegación de autonomía comparable (Patrone, 2018). Puede suponerse que las opiniones polarizadas entorpecen la urgente regulación internacional de la subrogación de útero para conseguir un balance entre obligaciones, responsabilidades, cuidado del consentimiento e impedimento de abusos hacia la mujer o la criatura gestada. Las feministas radicales responden que normalizar la prostitución o la subrogación es un mensaje para las mujeres del mañana: cuando padezcas precariedad económica, una salida tan llevadera como cualquier otro trabajo explotador la encontrarás en la fertilidad de tu útero o en comerciar con tu sexualidad. Si las reglas del mercado reemplazan las relaciones de cuidado apoyándose en la ficción del individuo propietario de sí, se desvanecerán las obligaciones estatales y comunitarias de cultivar un entorno de reciprocidad y apoyo mutuo (Pateman, 2002). Propiciar una iniciativa contraria a la normalización dirige un mensaje inequívoco, porque «donde no hay precedentes, una no puede imaginar alternativas a las condiciones actuales» (Lerner, 1986: 123).

Construir una crítica de la subrogación y defender la autonomía reproductiva es reivindicar públicamente que la experiencia gestacional pertenece a las mujeres involucradas. Aunque el contrato prometa prosperidad, la apropiación del embarazo se enraíza en un sistema opresivo que, a la vez, organiza las alternativas menos favorecedoras para mujeres doblemente oprimidas. Las elecciones son bien valoradas porque suponen un margen de acción incluso si tienen lugar en situaciones críticas. Sin embargo, el análisis macroscópico expone que, paralelamente, si- 
guen faltando muchos medios para amplificar la voz de muchas mujeres invisibilizadas (Frye, 1983: 54-58). Generar opciones de vida para la autonomía no equivale a elegir una alternativa de un sistema orientado por las reglas del mercado o por intereses masculinos. Por tanto, no hay pérdida de autonomía reproductiva provocada exclusivamente por elecciones desafortunadas con fallos que una negociación contractual pueda corregir. La autonomía es dañada por coerciones sociales que fomentan el control sobre las mujeres, creando dependencias indeseables que a menudo pasan desapercibidas.

Finalmente, respecto a la tentativa regulación, propongo una coda. Hay una separación temporal entre (re)pensar éticamente la subrogación bajo el prisma de las relaciones sociales significativas y su posterior deliberación, que decida su permisividad, restricción o prohibición. Sirva ese periodo para abrir brecha e ir rebatiendo cada aspecto de esta práctica que origine cosificación y sometimiento (Casado y Navarro-Michel, 2019: 41). El debate reflexivo incluye al feminismo radical, que desaprueba el contrato de subrogación por el contexto de opresión y por la apropiación de la voluntad corporal como fenómenos interrelacionados, como los barrotes de la jaula que desesperan al ave. Asimismo, teoriza que las lógicas masculinas del Estado son responsables y partícipes de tratar el cuerpo, la vida mental y emocional de las mujeres como objetos productores y proveedores de bienes; nutricios, moldeables, fértiles, disponibles. En el horizonte, el feminismo radical se propone cambiar el rumbo de una civilización cuya opresión maestra consiste en que las mujeres conciban su yo-cuerpo como una moneda o un regalo. Apunta, además, a disipar la confusión entre autonomía y libertad reproductiva con la transgresión (masculina) de los límites que resguardan los espacios de seguridad de las mujeres. Por ejemplo, sus recintos de convivencia social, los grupos de consciencia y activismo y, primordialmente, la integridad corporal como fuente de reflexión e individualidad. Prohibir y abolir prácticas con el propósito de proteger los espacios de resistencia puede priorizar la autonomía reproductiva de las mujeres, especialmente aquellas que no encuentran cobijo en su pertenencia a una clase poderosa (origen caucásico-blanco, clase alta). Concluyendo, algunas preguntas para abrir futuras exploraciones que reorienten el debate son: 1 ) ¿qué diferencias y coincidencias relevantes surgen entre la autonomía reproductiva masculina y su inclinación socialmente construida de cosificar el cuerpo reproductivo de las mujeres?; 2) ¿qué concepto de autonomía relacional es éticamente defendible en un sistema de discursos tecnológicos y cosificadores de las mujeres y de sus experiencias sexuales y reproductivas?; 3) ¿qué alternativa ética es aceptable frente a la asimetría de poder entre la madre gestante (menos posibilitada a invadir a las otras partes) y los contratantes/agencias intermediarias (con mayor acceso a invadir la vida de la embarazada)? Todas son preguntas innovadoras que una agenda de los derechos reproductivos debería estudiar seriamente ante el caso de la subrogación de útero.

\section{AGRADECIMIENTOS}

Este trabajo no hubiera sido posible sin la beca doctoral concedida por el Consejo Nacional de Ciencia y Tecnología de México. Además, gracias a Eduardo Zazo Jiménez por sus valiosos comentarios; a Marcela Reyes Ayala por su revisión, y a las dos evaluaciones anónimas por las críticas y observaciones que ayudaron a construir la versión final del ensayo.

\section{REFERENCIAS}

Álvarez-Medina, Silvina (2017). La autonomía reproductiva, relaciones de género, filiación y justicia. Revista jurídica de la Universidad Autónoma de Madrid, 35: 145-170. Disponible en https:// revistas.uam.es/revistajuridica/article/ view/8902

Alghrani, Amel y Harris, John (2006). Reproductive liberty: Should the foundation of families be regulated? Child and family law quarterly, 18 (2): 191-210.

Amorós, Celia (1987). Espacio de los iguales, espacio de las idénticas. Notas so- bre poder y principio de individuación. Arbor: ciencia, pensamiento y cultura. 128 (503): 113-127.

Anderson, Elizabeth (1995). Value in ethics and economics. Cambridge: Harvard University Press.

Anderson, Scott (2002). Prostitution and sexual autonomy: Making sense of the prohibition of prostitution. Ethics, 112 (4): 748-767. https://doi.org/10.1086/339672

Arneson, Richard (1992). Commodification and commercial surrogacy. Philosophy and public affairs, 21 (2): 132-164. https://www.jstor.org/stable/2265230
Beltrán, Elena (2017). Mi cuerpo, ¿de quién es? Propiedad y derechos sobre el cuerpo humano. Revista jurídica de la Universidad Autónoma de Madrid, 35 (1): 197-211.

Berkhout, Suze (2008). Buns in the oven. Objectification, surrogacy, and women's autonomy. Social theory and practice, 34 (1): 95-117. https://doi.org/10.5840/soctheorpract20083415

Casado, María y Navarro-Michel, Mónica (2019). Documento sobre gestación por sustitución. Barcelona: Edicions Universitat de Barcelona. 
De Lora, Pablo (2019). Lo sexual es político (y jurídico). Madrid: Alianza Editorial.

Dickenson, Donna (2017). Property in the body. Feminist perspectives. Cambridge: Cambridge University Press. https:// doi.org/10.1017/9781316675984

Dworkin, Andrea (1985). Right-wing women. Nueva York: Perigree Books.

Dworkin, Gerald (1972). Paternalism. The monist, 56 (1): 64-84. https://doi. org/10.5840/monist197256119

Dworkin, Ronald (1993). Life's dominion. Nueva York: Vintage

Evans, David (productor) (sin director asignado) (1991). Against pornography: The feminism of Andrea Dworkin. Reino Unido. British Broadcasting CorporationFilms Media Group. https://www. youtube.com/watch?v=L9j7-zZks08\&ab_ channel=RobertJensen.

Fabre, Cécile(2006). Whose bodyis itanyway? Justice and the integrity of the person. Oxford: Oxford University Press. https:// doi.org/10.1093/0199289999.001.0001

Field, Martha (1990). The case against the enforcement of surrogacy contracts. Politics and the life sciences, 8 (2): 199-204. https://doi.org/10.1017/ S0730938400009746

Frye, Marilyn (1983). The politics of reality. Essays in feminist theory. Berkeley: The Crossing Press.

Hanisch, Carol (1969/2000). The personal is political. En: Crow, Barbara (ed.) Radical feminism: A documentary reader. Nueva York y Londres: New York University Press, pp. 113-116.

Hanmer, Jalna (1987). Transforming consciousness: Women and the new reproductive technologies. En: Raymond, Janice y Corea, Gena; et. al. (eds.) Manmade women: How new reproductive technologies affect women. Bloomington: Indiana University Press, pp. 88-109.

Harris, John (2001). The value of life: An introduction to medical ethics. Londres: Routledge.

Lamm, Eleonora (2013). Gestación por sustitución: Ni maternidad subrogada ni alquiler de vientres. Barcelona: Edicions Universitat de Barcelona.

Leidholdt, Dorchen y Raymond, Janice (1990). The sexual liberals and the attack on feminism. Nueva York: Teachers College Press

Lerner, Gerda (1986). The creation of patriarchy. Nueva York: Oxford University Press

Lerner, Gerda (1993). The creation of feminist conciousness. From the middle ages to eighteen-seventy. Nueva York: Oxford University Press.

Lorde, Audre (1984/2007). Sister outsider. Berkeley: The crossing press.

MacKinnon, Catharine (1989). Toward a feminist theory of the state. Cambridge: Harvard University Press.

MacKinnon, Catharine (1990). Liberalism and the death of feminism. En: Leidholdt, Dorchen y Raymond, Janice (eds.) The sexual liberals and the attack on feminism. Nueva York: Teachers College Press, pp. 3-13.

Nussbaum, Martha (1999). Sex and social justice. Nueva York: Oxford University Press. https://doi.org/10.1093/ acprof:oso/9780195112108.001.0001

Olavarría, María Elena (2018). Personas que gestan para otros. Etnografía del trabajo reproductivo en México. Revista iberoamericana de antropología, 14 (3): 417-440. https:// doi.org/10.11156/aibr.140304

Oshana, Marina (1998). Personal autonomy and society. Journal of social philosophy, 29 (1): 81-102. https:// doi.org/10.1111/j.1467-9833.1998. tb00098.x

Panitch, Vida (2013). Surrogate tourism and reproductive rights. En: Hypatia, 28 (2): 274-289. https://doi.org/10.1111/ hypa.12005

Pateman, Carole (1988). The sexual contract. Londres: Polity Press

Pateman, Carole (1989). The disorder of women. Democracy, feminism and political theory. Stanford, California: Stanford University Press.

Pateman, Carole (2002). Self-ownership and property in the person. Democratization and a tale of two concepts. The journal of political philosophy. 10 (1): 20-53. https://doi. org/10.1111/1467-9760.00141

Patrone, Tatiana (2018). Is paid surrogacy a form of reproductive prostitution?
A kantian perspective. Cambridge quarterly of healthcare ethics, 27 (1): 109-122. https://doi.org/10.1017/ S0963180117000445

Phillips, Anne (2013). Our bodies, whose property? Princeton, EEUU: Princeton University Press. https://doi. org/10.1515/9781400846368

Ragoné, Helena (1997). Chasing the blood tie. Surrogate mothers, adoptive mothers, and fathers. En: Lamphere, Louise; Ragoné, Helena; Zavella, Patricia. (eds.) Situated lives. Gender and culture in everyday life. Nueva York y Londres: Routledge, pp. 110-127.

Raymond, Janice (1990a). Sexual and reproductive liberalism. En: Leidholdt, Dorchen y Raymond, Janice (eds.) The sexual liberals and the attack on feminism. Nueva York: Teachers College Press, pp. 104-111.

Raymond, Janice (1990b). Reproductive gifts and gift giving: the altruistic woman. The Hastings center report, 20 (6): 7-11. https://doi. org/10.2307/3563416

Raymond, Janice (1995). Women as wombs: Reproductive technologies and the battle over women's freedom. Melbourne: Spinifex Press.

Rich, Adrienne (1980). Compulsory heterosexuality and lesbian existance. Signs: journal of women in culture and society, 5 (4): 631-660. https://doi. org/10.1086/493756

Robertson, John (1994). Children of choice: Freedom and the new reproductive technologies. Princeton: Princeton University Press.

Robertson, John (1995). Liberalism and the limits of procreative liberty: A response to my critics. Washington and lee law review, 52 (1): 233-267.

Robertson, John (2004). Gay and lesbian access to assisted reproductive technology. Case western reserve law review, 55 (2): 323-372

Robertson, John (2016). Other women's wombs: Uterus transplants and gestational surrogacy. Journal of law and the biosciences, 3 (1): 68-86. https://doi.org/10.1093/jlb/lsw011

Satz, Debra (2010). Why some things should not be for sale. The moral limits of 
markets. Nueva York: Oxford University Press. https://doi.org/10.1093/ acprof:oso/9780195311594.001.0001

Shalev, Carmel (1989). Birth power. The case for surrogacy. New Haven: Yale University Press.

Shanley, Mary Lyndon (1993). «Surrogate mothering" and women's freedom: A critique of contracts for human reproduction. Signs: Journal of women in culture and society, 18 (3): 618-639. https://doi.org/10.1086/494822

Shanley, Mary Lyndon (2002). Making babies, making families. Boston: Beacon Press.

Smietana, Marcin (2017). Affective decommodifying, economic de-kinning:
Surrogates' and gay fathers' narratives in U.S. Surrogacy. Sociological research online, 22 (2): 1-13. https://doi. org $/ 10.5153 /$ sro. 4312

Straehle, Christine (2015). Is there a right to surrogacy? Journal of applied philosophy, 33 (2): 146-159. https:// doi.org/10.1111/japp.12145

Torres-Quiroga, Miguel Ángel (2019). Maternidad y gestación en venta: Fabricar bebés en la era neoliberal. Barcelona: Edicions Universitat de Barcelona.

Valcárcel, Amelia (2017). La agenda sobrevenida del feminismo. El País, 12 de junio. Disponible en https:// elpais.com/elpais/2017/05/25/ opinion/1495703140_313473.html
Wertheimer, Alan (1992). Two questions about surrogacy and exploitation. En: Philosophy and public affairs, 21 (3), pp. 211-239. https://doi. org/10.2307/2265356

Wilkinson, Stephen (2003). The exploitation argument against commercial surrogacy. Bioethics. 17 (2):169-187. https://doi. org/10.1111/1467-8519.00331

Wilkinson, Stephen (2016). Exploitation in paid surrogacy arrangements. Journal of applied philosophy, 33 (2): 125-145. https://doi.org/10.1111/japp.12138

Young, Iris Marion (1990). Justice and the politics of difference. Princeton: Princeton University Press. 